\title{
Style over substance: what can parenting styles tell us about ownership styles and obesity in companion animals?
}

\author{
Alexander J. German* \\ Department of Obesity and Endocrinology, Institute of Ageing and Chronic Disease, University of Liverpool, \\ Leahurst Campus, Chester High Road, Neston, Wirral CH64 7TE, UK \\ (Submitted 22 November 2013 - Final revision received 18 June 2014 - Accepted 1 July 2014 - First published online 21 November 2014)
}

\begin{abstract}
Obesity is a major medical concern in human subjects, and most concerning is the rapid recent increase in childhood obesity. Children are more likely to be obese if their parents are obese, an effect that is mediated both by genetics and environment, most notably parental influence. Four major parenting styles have been recognised: authoritative; authoritarian; indulgent; uninvolved. Too much parental control, as with the authoritarian style, is associated with a higher weight status in children. Conversely, indulgent feeding styles can also have negative consequences and, where control is too lax, a poor relationship with food develops, which may also lead to weight gain. Obesity is also a growing concern in companion animals, and it has parallels with obesity in children. For instance, overweight people are more likely to own overweight dogs. Furthermore, the care that people provide for their pets mirrors that which parents provide for children, and pets are commonly viewed as child substitutes. These similarities raise obvious questions about whether different styles of pet ownership exist, and what part they may play in attitudes to feeding as well as predisposition to obesity in pets. Future work could focus on determining to what extent styles of pet ownership mirror parenting styles, whether there are links to obesity in dogs and cats. Knowledge regarding the owner-pet bond might provide comparative insights into the links between parenting styles and childhood obesity.
\end{abstract}

\section{Key words: Overweight: Dogs: Cats: Childhood obesity}

\section{Obesity in the human population}

Obesity is a major concern to human health and is a global epidemic $^{(1)}$. Its major importance comes from the fact that it predisposes to many diseases, including type 2 diabetes mellitus, metabolic syndrome, CVD, arthritis and certain types of neoplasia. Whilst the rapid increase in the prevalence of adult obesity over the last 20 years has been alarming, of greatest concern is obesity in children, where there is a global trend for rapidly increasing prevalence ${ }^{(1)}$

\section{Parenting styles}

Various factors are said to be responsible for the development of childhood obesity including rapid early-life weight gain, socioeconomic status, time spent watching television and sleep duration ${ }^{(2,3)}$. In addition, parental weight status also exerts a strong positive influence on the weight status of their offspring, with obesity in children being more likely if their parents are obese ${ }^{(2)}$. This effect is thought to be related to both nature, through the transmission of genetic predispositions $^{(4)}$, and also nurture, not least the ways in which parents raise their children. One aspect relates to misperception of the body shape. In this respect, many obese people do not believe that they are overweight ${ }^{(5)}$, a misperception that is influenced by the parent's social environment ${ }^{(6)}$, which can affect compliance with weight-loss programmes ${ }^{(5)}$. Interestingly, parental misperception is also common, whereby they fail to recognise that their own child is overweight ${ }^{(7)}$.

A second aspect of nurture relates to feeding habits, use of food rewards and exercise. Indeed, the term 'family food environment' has been coined to summarise this very association $^{(8,9)}$. Understanding of such influences has improved in recent years with greater knowledge of parenting styles and behaviours. Parenting styles reflect differences in two major variables: the degree of control that the parent exerts on the behaviour of their child; the degree to which the parent responds to the needs and wishes of their child ${ }^{(10)}$. Based on the extent to which these variables are expressed, four different styles have been recognised: authoritative; authoritarian; indulgent; uninvolved ${ }^{(11)}$. Parents who make high

*Corresponding author: A. J. German, fax +44 151795 6101, email ajgerman@liv.ac.uk

This article was published as part of the WALTHAM International Nutritional Sciences Symposium Proceedings 2013.

This paper was published as part of a supplement to British Journal of Nutrition, publication of which was supported by an unrestricted educational grant from Mars Incorporated. The papers included in this supplement were invited by the Guest Editor and have undergone the standard journal formal review process. They may be cited. 
demands on their children and show little responsiveness to their opinions or wishes are said to display an authoritarian style. The authoritative style is demonstrated by parents who have reasonable expectations of their child, but display warmth and adapt their approach to the wishes of the child within certain boundaries. These parents typically use discussion, negotiation and reasoning ${ }^{(12)}$, as well as providing rationales for certain behaviours ${ }^{(13,14)}$, and praising the child when they behave appropriately ${ }^{(15)}$. In contrast to authoritarian and authoritative styles, the indulgent parenting style is one in which parents display warmth and respect their needs, but there is limited monitoring of the child's behaviour. Finally, the uninvolved (or 'neglectful') style is characterised by parents who place few demands on the behaviour of their child and are unaware of their child's needs or opinions. Of these, the authoritative style of parenting is associated with the positive outcomes regarding behaviour ${ }^{(11,16)}$; for instance, there are associations with greater maturity of the child, and greater academic achievement ${ }^{(17)}$.

The association between parenting styles, feeding behaviour and childhood obesity has also been examined. Indulgent feeding styles can have negative consequences because, when control is too lax, a poor relationship with food develops leading to weight gain ${ }^{(10)}$. In some studies, too much parental control, as with the authoritarian style, is also associated with higher weight status in the children ${ }^{(18)}$, suggesting that food restriction or pressuring children to eat certain foods can also be counterproductive ${ }^{(19)}$. A criticism of many of these studies is that they are cross-sectional and, therefore, causality cannot be assumed. Indeed, some prospective studies have questioned this association, and suggest that parents may well be exerting those restrictive/ authoritarian practices in direct response to observed characteristics in the child, such as a poor ability to selfregulate food intake $\mathrm{e}^{(20,21)}$, or concerns that they may already be overweight ${ }^{(22)}$. However, the findings of other longitudinal studies are consistent with a causative effect of restrictive practices; for instance, in one study ${ }^{(23)}$, pre-existing restrictive feeding practices predicted both an increased BMI, between 5 and 7 years of age, and a greater tendency to eat in the absence of hunger. These disparate findings can, perhaps, best be explained by the fact that the associations between restrictive feeding practices and both feeding behaviour and weight gain are complex. Indeed, one study ${ }^{(24)}$ demonstrated a possible two-way effect: for children who were predisposed to obesity, the presence of overweight status in children led to the adoption of restrictive feeding practices by parents, which, in turn, caused additional weight gain in the child. Similar findings were seen on other studies, which also suggest that parents' restrictive feeding practices are often implemented in response to their child being overweight or overeating that, in turn, leads to increased tendencies to overeat and eat when not hungry ${ }^{(23,25)}$.

\section{Obesity in companion animals}

As in human subjects, obesity is a growing concern in companion animals, with recent estimates suggesting that $34-59 \%$ of $\operatorname{dogs} s^{(26-28)}$ and $27-39 \%$ of cats ${ }^{(29-31)}$ are overweight or obese. The prevalence of obesity in companion animals has also been steadily increasing ${ }^{(32)}$. Also similar to human subjects, obesity predisposes affected companion animals to many diseases, including diabetes mellitus, osteoarthritis and respiratory disease ${ }^{(33)}$. Furthermore, metabolic derangements are known to occur ${ }^{(34-36)}$, whilst there are alterations in renal function ${ }^{(35)}$. All in all, obesity adversely affects the quality of life ${ }^{(36)}$ and shortens lifespan ${ }^{(37)}$.

There are many factors that predispose to obesity in companion animals, including certain endocrine diseases (e.g. hypothyroidism in dogs only; hyperadrenocorticism in both dogs and cats) ${ }^{(38)}$, neutering ${ }^{(39,40)}$ and genetics given known breed predispositions (e.g. Labrador retriever, cairn terrier, cavalier King Charles spaniel, Scottish terrier and cocker spaniel for dogs) ${ }^{(26)}$. Furthermore, various owner and lifestyle factors have been implicated including socioeconomic status, middle age, apartment dwelling, physical inactivity and a lesser interest in preventive veterinary care $^{(5,6,27,28,41-44)}$. A variety of dietary factors are also associated with companion animal obesity, including diet type and feeding treats and table scraps ${ }^{(5,6,27,28,41-47)}$. Owners of obese cats and dogs also observe them more closely during eating $^{(44,45)}$. Furthermore, cat owners commonly misunderstand feline behaviour; in the wild ancestors of domesticated cats, limited social interaction occurs during feeding; however, owners can mistakenly assume that a display of affection from their cat means that they are hungry and are asking for food ${ }^{(48)}$. If food is provided under such circumstances, the cat will learn to initiate contact to receive a food reward, causing overfeeding.

Treatment of obesity in companion animals involves dietary energy restriction, most commonly using a purposeformulated weight-loss diet, and increasing activity ${ }^{(49,50)}$ There are notable benefits to weight loss with evidence for improved mobility (in obsess dogs with concurrent osteoarthritis) ${ }^{(51)}$, improved insulin sensitivity ${ }^{(34,52,53)}$ and better quality of life ${ }^{(36)}$. However, there is a mistaken assumption that weight loss is a straightforward process, with many veterinarians often believing that simply telling an owner to make sure their pet 'eats less and exercises more' will be successful. The reality is that it can be immensely challenging to ensure that a pet loses weight successfully, and the role of the owner is critical. In this respect, owners are responsible for controlling food intake whilst, at the same time, increasing their pet's physical activity $^{(49,50)}$. Weight loss progresses slowly (typically $<1 \%$ / week) and often requires aggressive energy restriction ${ }^{(49,50)}$. This can prove challenging to the owner who may become frustrated with an apparent lack of progress, or find it difficult to resist their pet when begging activity increases as a result of energy restriction. Not surprisingly, therefore, non-compliance is a major problem ${ }^{(48)}$, with many owners feeding additional food against recommendations ${ }^{(49,50)}$. Furthermore, many owners choose to discontinue their pet's weight-loss regimen before reaching target weight; indeed, only half of dogs that commence a weight-loss programme successfully complete it $^{(54,55)}$. Moreover, challenges for the owner exist even after the weight-loss period, because approximately half of dogs 
that successfully reach target weight subsequently rebound ${ }^{(56)}$ Therefore, far from this being a simple process with almostperfect success, it is the minority of obese pet dogs that successfully lose weight, return to optimal condition and then keep the weight off. Many of the challenges evident in companion animal weight-loss programmes are similar to those faced by people who attempt to lose weight by restricting food intake. Indeed, long-term weight-loss success is disappointing with dietary management in human subjects, with studies suggesting that most participants ultimately fail and up to two-thirds actually regain more weight than they originally lost ${ }^{(57)}$. Dietary factors play a crucial role because poor eating restraint is associated with the likelihood of rebound ${ }^{(58,59)}$.

Therefore, notable parallels exist between human and companion animal obesity, and this is not surprising for outbred species sharing the same environment. However, more specifically, obesity in pets may be an intriguing model for childhood obesity. In this respect, the care that people provide for their pets mirrors that which parents provide for children. Indeed, there are similarities between the interactions between owners and their dogs, and between parent and child $^{(60)}$. The owners of obese pets tend to overhumanise them ${ }^{(44,45)}$, and pets are often viewed as substitutes for children $^{(61)}$. Furthermore, the dogs of overweight people are more likely to be overweight than the dogs of owners who are not overweight ${ }^{(62,63)}$ and, as is the case with parents misperceiving the body shape of their children, misperception of the body shape is also seen in pet owners ${ }^{(64,65)}$. Owners 'normalise' their animal's body condition, where most owners of overweight dogs underestimate their dog's body condition $^{(64,65)}$. Therefore, given the known impact that parenting styles have on childhood obesity, it raises obvious questions about whether different styles of dog ownership exist, and what part they may play in attitudes to feeding as well as predisposition to obesity in pets.

\section{Mapping parenting styles to pet ownership styles}

Unfortunately, limited information exists in the veterinary literature regarding styles of pet ownership. One recent study $^{(66)}$ suggested that owners typically display one of three different 'orientations' towards their pet, namely 'dominionistic', 'humanistic' or 'protectionistic'. Dominionistic owners value pets in terms of their functional value (e.g. protection); humanistic owners view their pets as surrogate human beings and have a close attachment; and protectionistic owners have a general high regard for animals, and all pets, viewing them as valuable companions and free-thinking creatures. However, it is unclear as to whether and how such orientations relate to the parenting styles described earlier. Although to the author's knowledge, there has been no attempt to relate such styles to companion animal obesity, there are striking similarities with known observed patterns of dog ownership (Table 1). Nevertheless, given the lack of research in this field, it is an area in much need of development.

Clearly, therefore, the veterinary and animal nutrition community have a lot to learn about the basics of pet ownership styles. A lot of fundamental work is required, and there are many unanswered questions. For instance, it would be fascinating to know whether styles of pet ownership do indeed mirror the recognised parenting styles. It would also be of interest to compare the styles of owners of different pet species, and even different breeds within a species. Finally, for adults who are both parents and pet owners, it would be fascinating to determine to what extent their style of pet ownership mirrors their parenting style.

\section{How can pet ownership styles help improve our understanding of causes of obesity?}

So, how might the concept of ownership styles help with the topic of pet obesity? First, as with parenting styles and

Table 1. Key characteristics of human parenting styles ${ }^{(10)}$ and possible parallels with pet ownership

\begin{tabular}{|c|c|c|}
\hline Parenting style & Associated feeding style & $\begin{array}{l}\text { Possible examples of equivalent pet } \\
\text { ownership styles }\end{array}$ \\
\hline Authoritarian & $\begin{array}{l}\text { Encourage eating using highly directive } \\
\text { behaviours and are unsupportive }\end{array}$ & $\begin{array}{l}\text { Consistency (time and type of food) } \\
\text { No or few treats } \\
\text { Food used to exert dominance (e.g. making a pet wait } \\
\text { before commencing eating) }\end{array}$ \\
\hline Authoritative & $\begin{array}{l}\text { Actively encourage eating using non- } \\
\text { directive and supportive behaviours }\end{array}$ & $\begin{array}{l}\text { Consistency (time and type of food) } \\
\text { Positive encouragement to eat right food } \\
\text { Occasional functional treats (e.g. dental chews) } \\
\text { Treats used in a positive way (e.g. behaviour training) } \\
\text { No table scraps given }\end{array}$ \\
\hline Indulgent & $\begin{array}{l}\text { Make few demands to eat but } \\
\text { those demands are supportive }\end{array}$ & $\begin{array}{l}\text { Type and timing if food determined by pet } \\
\text { Diet altered to suit pet's preferences } \\
\text { Treats and table scraps frequently used } \\
\text { Owner feeds pet by hand }\end{array}$ \\
\hline Uninvolved & $\begin{array}{l}\text { Make few demands on children to } \\
\text { eat and are unsupportive }\end{array}$ & $\begin{array}{l}\text { Owner shows little interest in pet } \\
\text { Outdoor living pet (cat), sporadically visits at meal times } \\
\text { Diet variable in amount and feed times } \\
\text { Type of food determined by cost/convenience }\end{array}$ \\
\hline
\end{tabular}


childhood obesity, it would be worth determining whether different styles of pet ownership predisposed to obesity. A greater understanding might also help us to understand better what factors are associated with the failure of weight-loss programmes in obesity animals, most notably the high non-compliance and rebound rates ${ }^{(54-56,67)}$. It would be fascinating to explore the extent to which styles of pet ownership may influence success with weight programmes. In this respect, most current weight management strategies require the owner to exert control over both the amount and type of food fed, and also the denial of certain foods (including treats), akin to an authoritarian style. Owners with other styles might find such strategies difficult to adopt, predisposing them to fail. Most problematic would likely be those preferring and indulgent feeding style. Furthermore, although the use of an authoritarian style may enable other clients to succeed in slimming their pet, this strategy might then increase the likelihood of subsequent regain during the maintenance phase. Those foods denied during weight loss become more desirable for both the pet (increasing the likelihood of food stealing or consumption in excess if offered) and the owner (because a period of denying such food might increase the desire of the owner subsequently to feed it as a reward). A final question regarding effects of pet ownership on weight management would be to what extent pet ownership styles could be changed by education. If, like parenting styles, certain styles of pet ownership were known both to predispose to weight gain, and to adversely affect weight-loss outcomes, would it be possible to train an owner to adopt a different style?

A further challenge for companion animal weight management is the reluctance of veterinarians to discuss the topic of obesity with clients, as highlighted by a recent study suggesting that the topic is raised in only $1.4 \%$ of veterinary consultations $^{(68)}$. Given the current prevalence in dogs and cats (see previous text), many owners of overweight companion animals receive limited guidance from their veterinarian regarding optimal body condition. The reasons why veterinarians are reluctant to discuss the overweight status of a pet with their owner are not known, but might partly be due to concerns about offending the owner. Such reluctance might arguably be greater when owners are themselves overweight, not least given the positive association between BMI in owners and the body condition of their dog exists $^{(62,63)}$. Clearly, therefore, this is a topic that many veterinarians find challenging and difficult to raise with clients. It is possible that knowledge of pet ownership styles could help. In this respect, if a veterinarian could identify the style of ownership, it might be possible to tailor their approach. In time, specific strategies could be developed for different owner styles, enabling greater tailoring of the approach than is currently possible.

Finally, knowledge of pet ownership styles could ultimately be used to help in obesity prevention. If certain styles were known to predispose to obesity, then targeted owner education could be applied to those owners with styles likely to predispose to weight gain. A recent study has identified that different populations of cat exist that respond differently to long-term ad libitum feeding ${ }^{(69)}$. Some cats are unable to regulate their food intake, leading to gradual lifelong weight gain, whilst others maintain stable weight and optimal body condition lifelong, presumably by regulating intake. Therefore, this work suggests that different groups of cat have different feeding styles, some of which are regulators, whilst others tend to overeat. When it comes to preventing weight gain, attention should be paid for matching pet ownership style to feeding style. For example, an owner with an indulgent feeding style might not be a good match for a cat that overeats, but might be fine if they were to own a cat that regulates; the owner could be free to feed what they wish, without the risk of undesirable weight gain developing in their cat. Instead, a better match for an overeating cat might be an owner with an authoritative style. Such an owner would provide consistency in terms of timing and amount of food provided and, thus, provide external control to ensure that an ideal weight is maintained.

\section{Conclusions}

In summary, the concept of parenting styles and its role in childhood obesity is fascinating, and knowledge developed in this field may have relevance to pets, not least those prone to obesity. It remains to be seen to what extent these styles are mirrored in pet populations, and what use we can make of such knowledge.

\section{Acknowledgements}

The author wishes to thank Theresa Nicklas (Baylor College, Houston, TX, USA) for preliminary discussions that lead to the initial draft of this manuscript.

The present paper is based on a presentation given at the WALTHAM International Nutritional Sciences Symposium, Portland, OR, USA, September 2013. The author's expenses were paid for attending that meeting, which included speaker honorarium.

Royal Canin also financially supports the author's academic post at the University of Liverpool.

Contribution of author is as follows: It was written solely by A. J. G. after initial discussions on the topic of parenting style, with Theresa Nicklas.

\section{References}

1. Wang Y \& Lobstein L (2006) Worldwide trends in childhood overweight and obesity. Int J Pediatr Obes 1, 11-25.

2. Danielzik S, Czerwinski-Mast M, Langnase K, et al. (2004) Parental overweight, socioeconomic status and high birth weight are the major determinants of overweight and obesity in 5-7y-old children: baseline data of the Kiel Obesity Prevention Study (KOPS). Int J Obes Relat Metab Disord 28, 1494-1502.

3. Reilly JJ, Armstrong J, Dorosty AR, et al. (2005) Early life risk factors for obesity in childhood: cohort study. BMJ $\mathbf{3 3 0}$, 1357-1359.

4. Frayling TM, Timpson NJ, Weedon MN, et al. (2007) A common variant in the FTO gene is associated with body 
mass index and predisposes to childhood and adult obesity. Science 316, 889-894.

5. Kuchler F \& Variyam J (2002) Misperceptions in self-assessed weight status vary along demographic lines. Food Rev $\mathbf{2 5}$, 21-26.

6. Johnson F, Cooke L, Croker H, et al. (2008) Changing perceptions of weight in Great Britain: comparison of two population surveys. BMJ 337, 270-272.

7. Doolen J, Alpert PT \& Miller SK (2009) Parental disconnect between perceived and actual weight status of children: a metasynthesis of the current research. J Am Acad Nurse Pract 21, 160-166.

8. Birch LL \& Davison KK (2001) Family environmental factors influencing the developing behavioral controls of food intake and childhood overweight. Pediatr Clin North Am 48, 893-907.

9. Campbell KJ, Crawford DA \& Ball K (2006) Family food environment and dietary behaviors likely to promote fatness in 5-6 year-old children. Int J Obes (Lond) 30, 1272-1280.

10. Hughes SO, Power TG, Orlet Fisher J, et al. (2005) Revisiting a neglected construct: parenting styles in a child-feeding context. Appetite 44, 83-92.

11. Maccoby E \& Martin J (1983) Socialization in the context of the family: parent-child interaction. In Handbook of Child Psychology, pp. 1-101 [PH Mussen, editor]. New York: Wiley.

12. Iannotti RJ, O'Brien RW \& Spillman DM (1994) Parental and peer influences on food consumption of preschool African-American children. Percept Mot Skills 79, 747-752.

13. Cousins JH, Power TG \& Olvera-Ezzell N (1993) Mexican-American mothers' socialization strategies: effects of education, acculturation, and health locus of control. J Exp Child Psychol 55, 258-276.

14. Heptinstall E, Puckering C, Skuse D, et al. (1987) Nutrition and mealtime behaviour in families of growth-retarded children. Hum Nutr Appl Nutr 41, 390-402.

15. Stanek K, Abbott D \& Cramer S (1990) Diet quality and the eating environment of preschool children. J Am Diet Assoc 90, 1582-1584.

16. Darling N \& Steinberg I (1993) Parenting style as context: an integrative model. Psych Bull 113, 487-496.

17. Mandara J (2003) The typological approach in child and family psychology: a review of theory, methods, and research. Clin Child Fam Psychol Rev 6, 129-146.

18. Faith MS, Scanlon KS, Birch LL, et al. (2004) Parent-child feeding strategies and their relationships to child eating and weight status. Obes Res 12, 1711-1722.

19. Ventura AK \& Birch LL (2008) Does parenting effect children's eating and weight status? Int J Behav Nutr Phys Act 5, 1-12.

20. Webber L, Cooke L, Hill C, et al. (2010) Child adiposity and maternal feeding practices: a longitudinal analysis. Am J Clin Nutr 92, 1423-1428.

21. Webber L, Cooke L, Hill C, et al. (2010) Associations between children's appetitive traits and maternal feeding practices. J Am Diet Assoc 110, 1718-1722.

22. Francis LA, Hofer SM \& Birch LL (2001) Predictors of maternal child-feeding style: maternal and child characteristics. Appetite 37, 231-243.

23. Birch LL, Fisher JO \& Davison KK (2003) Learning to overeat: maternal use of restrictive feeding practices promotes girls' eating in the absence of hunger. Am J Clin Nutr 78, 215-220.

24. Faith MS, Berkowitz RI, Stallings VA, et al. (2004) Parental feeding attitudes and styles and child body mass index: prospective analysis of a gene-environment interaction. Pediatrics 114, e429-e436.

25. Rodgers RF, Paxton SJ, Massey R, et al. (2013) Maternal feeding practices predict weight gain and obesogenic eating behaviors in young children: a prospective study. Int $J$ Behav Nutr Phys Act 10, 24.

26. Lund EM, Armstrong PJ, Kirk CA, et al. (2006) Prevalence and risk factors for obesity in adult dogs from private US veterinary practices. Int J Appl Res Vet Med 4, 177-186.

27. Colliard L, Ancel J, Benet JJ, et al. (2006) Risk factors for obesity in dogs in France. J Nutr 136, 1951S-1954S.

28. Courcier EA, Thomson RM, Mellor DJ, et al. (2010) An epidemiological study of environmental factors associated with canine obesity. J Small Anim Pract 51, 362-367.

29. Lund EM, Armstrong PJ, Kirk CA, et al. (2005) Prevalence and risk factors for obesity in adult cats from private US veterinary practices. Int J Appl Res Vet Med 3, 88-96.

30. Colliard L, Paragon BM, Lemuet B, et al. (2009) Prevalence and risk factors of obesity in an urban population of healthy cats. J Feline Med Surg 11, 135-140.

31. Courcier EA, Mellor DJ, Pendlebury E, et al. (2012) An investigation into the epidemiology of feline obesity in Great Britain: results of a cross-sectional study of 47 companion animal practises. Vet Rec 171, 560-564.

32. Banfield Pet Hospital ${ }^{\mathrm{TM}}$ (2012) State of pet health 2012 report. http://www.stateofpethealth.com/Content/pdf/State_ of_Pet_Health_2012.pdf (accessed October 2013)

33. German AJ (2006) The growing problem of obesity in dogs and cats. J Nutr 136, 1940S-1946S.

34. Tvarijonaviciute A, Ceron JJ, Holden SL, et al. (2013) Obesityrelated metabolic dysfunction in dogs: a comparison with human metabolic syndrome. BMC Vet Res $\mathbf{8}, 147$.

35. Tvarijonaviciute A, Ceron JJ, Holden SL, et al. (2013) Effect of weight loss in obese dogs on indicators of renal function or disease. J Vet Intern Med 27, 31-38.

36. German AJ, Holden SL, Wiseman-Orr ML, et al. (2012) Quality of life is reduced in obese dogs but improves after successful weight loss. Vet J 192, 428-434.

37. Kealy RD, Lawler DF, Ballam JM, et al. (2002) Effects of diet restriction on life span and age-related changes in dogs. J Am Vet Med Assoc 220, 1315-1320.

38. Panciera DL (1994) Hypothyroidism in dogs: 66 cases (1987-1992). J Am Vet Med Assoc 204, 761-767.

39. Hart BL \& Barrett RE (1973) Effects of castration on fighting, roaming and urine spraying in adult male cats. J Am Vet Med Assoc 163, 290-292.

40. Nguyen PG, Dumon HJ, Siliart BS, et al. (2004) Effects of dietary fat and energy on body weight and composition after gonadectomy in cats. Am J Vet Res 65, 1708-1713.

41. Robertson ID (1999) The influence of diet and other factors on owner-perceived obesity in privately owned cats from metropolitan Perth, Western Australia. Prev Vet Med 40, $75-85$.

42. Robertson ID (2003) The association of exercise, diet and other factors with owner-perceived obesity in privately owned dogs from metropolitan Perth, WA. Prev Vet Med 58, $75-83$.

43. Allan FJ, Pfeiffer DU, Jones BR, et al. (2000) A cross-sectional study of risk factors for obesity in cats in New Zealand. Prev Vet Med 46, 183-196.

44. Kienzle E, Bergler R \& Mandernach A (1998) Comparison of the feeding behavior and the human-animal relationship in owners of normal and obese dogs. J Nutr 128, 2779S-2782S.

45. Kienzle E \& Bergler R (2006) Human-animal relationship of owners of normal and overweight cats. J Nutr 136, 1947S-1950S

46. Russell K, Sabin R, Holt S, et al. (2000) Influence of feeding regimen on body condition in the cat. J Small Anim Pract 41, 12-17. 
47. Backus RC, Cave NJ \& Keisler DH (2007) Gonadectomy and high dietary fat but not high dietary carbohydrate induce gains in body weight and fat of domestic cats. $\mathrm{Br}$ J Nutr 98, 641-665.

48. Heath S (2005) Behaviour problems and welfare. In The Welfare of Cats, pp. 91-118 [I Rochlitz, editor]. London: Springer.

49. German AJ, Holden SL, Bissot T, et al. (2007) Dietary energy restriction and successful weight loss in obese client-owned dogs. J Vet Intern Med 21, 1174-1180.

50. German AJ, Holden SL, Bissot T, et al. (2008) Changes in body composition during weight loss in obese client-owned cats: loss of lean tissue mass correlates with overall percentage of weight lost. J Feline Med Surg 10, 452-459.

51. Marshall WG, Hazewinkel HAW, Mullen D, et al. (2010) The effect of weight loss on lameness in obese dogs with osteoarthritis. Vet Res Commun 34, 241-253.

52. German AJ, Hervera M, Hunter L, et al. (2009) Improvement in insulin resistance and reduction in plasma inflammatory adipokines after weight loss in obese dogs. Domest Anim Endocrinol 37, 214-226.

53. Tvarijonaviciute A, Ceron JJ, Holden SL, et al. (2012) Effects of weight loss in obese cats on biochemical analytes relating to inflammation and glucose homeostasis. Domest Anim Endocrinol 42, 129-141.

54. Gentry SJ (1993) Results of the clinical use of a standardized weight-loss program in dogs and cats. J Am Anim Hosp Assoc 29, 369-375.

55. Yaissle JE, Holloway C \& Buffington CAT (2004) Evaluation of owner education as a component of obesity treatment programs for dogs. J Am Vet Med Assoc 224, 1932-1935.

56. German AJ, Holden SL, Morris PJ, et al. (2012) Long-term follow-up after weight management in obese dogs: the role of diet in preventing weight regain. Vet J 192, 65-70.

57. Mann T, Tomiyama J, Westling E, et al. (2007) Medicare's search for effective obesity treatments: diets are not the answer. Am Psychol 62, 220-233.
58. Wing RR \& Hill JO (2001) Successful weight loss maintenance. Annu Rev Nutr 21, 323-341.

59. McGuire MT, Wing RR, Klem ML, et al. (1999) What predicts weight regain in a group of successful weight losers? J Consult Clin Psychol 67, 177-185.

60. Archer J (1997) Why do people love their pets? Evol hum behav 18, 237-259.

61. Charles N \& Davies CA (2008) My family and other animals: pets as kin. Sociol Res Onlin 13, 4. DOI: 10.5153/ sro. 1798

62. Holmes KL, Morris PJ, Abdulla Z, et al. (2007) Risk factors associated with excess body weight in dogs in the UK. J Anim Physiol Anim Nutr 91, 166-167.

63. Nijland ML, Stam F \& Seidell JC (2010) Overweight in dogs, but not in cats, is related to overweight in their owners. Public Health Nutr 13, 102-106.

64. Courcier EA, Mellor DJ \& Thomson RM (2011) A cross sectional study of the prevalence and risk factors for owner misperception of canine body shape in first opinion practice in Glasgow. Prev Vet Med 102, 66-74.

65. Eastland-Jones R, German AJ, Holden SL, et al. (2014) Owner misperception of canine body condition persists despite use of BCS chart. J Nutr Sci (In the Press).

66. Blouin DB (2013) Are dogs children, companions, or just animals? Understanding variations in people's orientations toward animals. Anthrozoois 26, 279-294.

67. Deagle G, Holden SL, Biourge V, et al. (2014) Investigating long-term outcomes of weight management in obese cats. $J$ Nutr Sci (In the Press)

68. Rolph NC, Noble PJM \& German AJ (2014) How often do primary care veterinarians record the overweight status of dogs? J Nutr Sci (In the Press)

69. Serisier S, Feugier A, Venet C, et al. (2013) Faster growth rate in ad libitum-fed cats: a risk factor predicting the likelihood of becoming overweight during adulthood. J Nutr Sci 2, e11. 